\title{
Metodologia Não Destrutiva de Parametrização da Queima do Zinco no Processo de Soldagem a Ponto por Resistência
}

\author{
Adriano Cássio Baldim ${ }^{1}$, Sebastião Carlos da Costa $^{1}$, Thairone Conti Serafini Aguiar ${ }^{1}$ \\ 1 Laboratório de Soldagem, Instituto de Engenharia Mecânica, Universidade Federal de Itajubá - UNIFEI, Itajubá, MG, Brasil.
}

Recebido: 12 Dez., 2014

Aceito: 23 Mar., 2015

E-mails:

adriano_baldim@yahoo.com.br(ACB), sccosta@unifei.edu.br (SCC), thaironemg@hotmail.com (TCSA)
Este é um artigo publicado em acesso aberto (Open Access) sob a licença Creative Commons Attribution Non-Commercia que permite uso, distribuição e reproduç̧ăo em qualq'uer meio, sem restriçōes desde que sem fins comerciais e que 0 trabalho original seja corretamente citado.
Resumo: Os aços galvanizados são utilizados em grande número, principalmente nas indústrias automotivas, pela sua resistência à corrosão e baixo custo. A soldagem destes materiais, neste setor industrial, normalmente é realizada através do processo de soldagem a ponto. Em função dos aços galvanizados apresentarem uma camada de cobertura à base de zinco, normalmente utiliza-se durante soldagem, uma técnica denominada burn zinc (queima do zinco), para minimizar os efeitos prejudiciais do zinco neste material, durante o ciclo de soldagem. Neste contexto, este trabalho estudou um método não destrutivo, com o objetivo de encontrar uma adequada remoção desta camada de zinco, considerando para isto, os sinais gerados por um sensor que registra o deslocamento do eletrodo durante as fases do processo de solda a ponto, utilizando como base a leitura da expansão térmica da chapa de aço galvanizado. Assim, experimentos de simulação física foram feitos, variando a corrente e o tempo de ciclo da fase de preaquecimento. As respostas de burn zinc geradas pelo sensor e as análises visuais por atributo, foram mostradas em gráficos através de um envelope operacional. Evidências mostraram que o sinal de deslocamento do eletrodo, mostrou ser um eficiente método não destrutivo para a determinação de parâmetros adequados de burn zinc no processo de solda a ponto para chapas de aço galvanizadas.

Palavras-chave: Aço galvanizado; Deslocamento do eletrodo; Queima do zinco; Soldagem a ponto.

\section{Non Destructive Methodology for Parameterization of the Burning Zinc in the Resistance Spot Welding Process}

\begin{abstract}
Galvanized steel is used in large numbers, especially in the automotive, for its corrosion resistance and low cost. The welding of these materials, this industrial sector is usually performed through the spot welding process. Depending on the galvanized steel with a film of coating based on zinc is usually used in welding, a technique called burn zinc (zinc burning) to minimize the detrimental effects of zinc in the material during the welding cycle. In this context, this paper studied a non-destructive method, aiming to find an appropriate removal of this layer of zinc, for considering this, the signals generated by a sensor that records the dislodgement during stages of the spot welding, using as a basis the reading of the thermal expansion of galvanized steel sheet. Thus, physical simulation experiments were performed by varying the current and the time for the preheating phase cycle. The responses from the burn zinc generated by the sensor and visual analysis by attribute, were shown in graphs through an operating envelope. Evidence showed that the sign of displacement of the electrode, proved to be an efficient non-destructive method for determining the appropriate parameters in the burn zinc in process of spot welding for galvanized steel plates.
\end{abstract}

Key-words: Galvanized steel; Electrode displacement; Burning zinc; Welding point.

\section{Introdução}

As investigações científicas ligadas aos processos de soldagem são de extrema importância para o avanço tecnológico na área de fabricação mecânica. Por se tratar de um processo industrial de produção, grandes investimentos são necessários e, a redução de custos assume um papel importante. Neste sentido, dentro dos processos de soldagem existentes, o processo de solda a ponto por resistência elétrica ( $R S W$ do inglês Resistance Spot Welding) se destaca como um dos mais utilizados em indústrias automobilísticas, eletrônicas, entre outras de bens manufaturados [1]. Os aspectos como alta produtividade, facilidade de operação e automação, possibilidades de união de chapas 
finas, não utilização de consumíveis, rapidez de execução associado a um baixo custo possibilita que a soldagem a ponto por resistência seja utilizada na união de estruturas com geometrias complexas, onde se faz necessária uma boa resistência mecânica, abrindo possibilidades para a obtenção de produtos de alta qualidade [2].

Dentre os tipos de materiais utilizados, o aço galvanizado se destaca pela sua resistência à corrosão devido ao revestimento de zinco. Sabe-se, todavia que, do ponto de vista da soldabilidade, este revestimento de zinco presente torna-se um fator complicador, pois além de causar um desgaste prematuro dos eletrodos aumentando a instabilidade do processo, também dificulta o controle dos parâmetros que garantem soldas de qualidade [3,4]. Isto é devido as suas características metalúrgicas e elétricas que impõem dificuldades na operação de soldagem, podendo comprometer a qualidade final da solda realizada. Neste contexto, [5] observaram que, o amassamento das asperezas do zinco, provocada pela pressão dos eletrodos contribui para a redução da resistência de contato entre chapas e, entre eletrodo e chapa. Já [6] descreveram que a menor resistividade elétrica apresentada pelo zinco justifica a utilização de níveis maiores de correntes necessárias à formação do ponto de solda. Além disto, a formação do latão ocasionada pela difusão do zinco para o cobre resulta em uma maior geração de calor na ponta do eletrodo devido a menor condutividade térmica do latão. Fato este, contribui para o aumento da indentação na superfície do material e, acelera o processo de deterioração do eletrodo que tem relação direta com a densidade de corrente [4]. Assim, a busca por condições de soldagem que propiciem uma remoção adequada do revestimento de zinco em chapas de aço galvanizadas, tem sido o alvo dos trabalhos de vários pesquisadores.

Atualmente, os processos de garantia da qualidade se dão pela destruição da solda, a medição do diâmetro do ponto e a definição do modo de falha dos corpos de prova. As avaliações de qualidade baseadas em ensaios destrutivos são consideradas muitas vezes ineficazes pelo fato de serem aplicadas a um pequeno número de amostras, fora da linha de produção. Levando isso em conta, em muitos dos projetos, são aplicados pontos de solda extras, com o intuito de reduzir os riscos de falha da solda, o que acaba acarretando em custos excedentes. Com base neste aspecto, existe uma demanda natural de otimização do processo de solda a ponto, pelo monitoramento da qualidade de soldagem de forma não destrutiva [7]. [8] afirmam que a separação dos eletrodos fornece o sinal mais efetivo para estimação da formação do ponto de solda devido à expansão térmica, o que o torna ideal para estimar sua resistência. Por outro lado, na literatura existem criticas quanto à utilização deste método, referentes a possíveis dificuldades de calibração e manutenção do equipamento de medição, na robustez do sistema em aplicações industriais e nos custos elevados dos equipamentos $[9,10]$.

Todavia, a aplicação deste método na fase de preaquecimento não tem sido bem estudada. Neste sentido, este trabalho tem como objetivo estudar um método não destrutivo de monitoramento da fase de preaquecimento onde há a remoção da camada de zinco, com base na leitura do deslocamento do eletrodo, originado pela expansão térmica do metal.

\section{Materiais e Métodos}

Para se atingir os objetivos estabelecidos, este trabalho se dividirá em duas etapas distintas, onde os testes foram realizados de forma experimental e, os parâmetros foram escolhidos de forma aleatória. Vale ressaltar que o ponto crucial da soldagem a ponto de aços galvanizados, se refere à quebra da camada de zinco. Em sua primeira etapa, este trabalho pretende validar uma metodologia baseada em um sensor de deslocamento para caracterizar a ação de quebra da camada de zinco, considerando para isto informações descritas em [3]. Estabelecida a metodologia para caracterização da quebra da camada de zinco, este trabalho pretende na segunda etapa avaliar a influência dos parâmetros de corrente e tempo durante a pré-fase (dita preaquecimento), na eficiência da remoção da camada de zinco, procurando assim desenvolver um envelope operacional (que é um conjunto de parâmetros) para ajuste dos parâmetros influentes.

Sendo assim, para a primeira e segunda etapas, todos os testes preliminares foram realizados por uma máquina de solda a ponto estacionária marca Presol Transweld, modelo TWPRV50 com potência nominal de $50 \mathrm{kVA}$, alimentação de $220 \mathrm{~V}$ e corrente máxima de $6 \mathrm{kA}$, cujos detalhes de seus principais acessórios são mostrados na Figura 1a. O equipamento de solda utilizado possui a capacidade de ajuste de forma independente de 15 parâmetros diferentes, permitindo assim ativar somente o preaquecimento, composto pelo tempo (ciclos) e corrente (kA) de preaquecimento. Neste contexto, é importante resaltar que no Brasil, cada ciclo tem um tempo (período) de 16,66 milissegundos (ms) que equivale a 0,01666 segundos. 
Juntamente ao equipamento de soldagem a ponto, foi acoplado um transdutor diferencial de deslocamento linear (LVDT), modelo GA-HD LBB315PA-100-M, fabricante Metrolog ${ }^{\circledR}$, com suporte do eixo por rolamento linear de precisão, avanço do êmbolo por mola e apalpador de carbono-tungstênio com repetibilidade de $0,0001 \mathrm{~mm}$ e campo de medição de $+/-2,5 \mathrm{~mm}$. Pode-se observar na Figura $1 \mathrm{~b}$ que o sensor do sistema de medição, foi adaptado ao cabeçote móvel da máquina de solda. Este por sua vez, está conectado ao cilindro pneumático que efetua o movimento do eletrodo superior.

O deslocamento linear do transdutor é medido através de uma interface composta por um sistema de aquisição dos dados composto por um condicionador digital Metrolog modelo SD20 com saída USB, sensores LVDT e conversor A/D 24-bits. A Figura 1c mostra a disposição do sistema de interface com o software de parametrização e a visualização on-line do deslocamento do eletrodo na tela de um computador, através do software SD20 Data Logger ${ }^{\circledR}$. Os corpos de prova utilizados constituem-se de chapas de aço carbono com espessura de $1 \mathrm{~mm}$, galvanizado por eletrodeposição cuja composição química quantidade de zinco é mostrada na Tabela 1.

As amostras foram cortadas nas dimensões $105 \times 45 \mathrm{~mm}$ conforme recomendações da norma [11]. Posteriormente, foram limpas somente com um tecido de algodão. Muito embora este procedimento não seja utilizado no ambiente industrial, neste experimento foi considerado com o intuito de eliminar a possibilidade de qualquer interferência nos resustados que possa ser causada por óleos e sujeiras. Em seguida, as amostras foram dispostas para o experimento. A Figura 2 mostra os detalhes desta preparação.

O eletrodo utilizado possui um formato em cone truncado a $15^{\circ}$, diâmetro da ponta de $5 \mathrm{~mm}$, Grupo A, classe 2 (cobre cromo zircônio) [12] e, para refrigerá-los durante o processo, uma vazão d'água de $8 \mathrm{I} / \mathrm{min}$. foi ajustada. Como procedimento de soldagem, procurou-se garantir que em cada etapa do experimento realizado, as pontas dos eletrodos fossem usinadas para o diâmetro original, antes da execução dos testes. A condição final do eletrodo, após sua fresagem, é mostrada na Figura 3.

Na primeira etapa, os valores para a parametrização do equipamento foram regulados de acordo com o mostrado na Tabela 2. Os impulsos de solda se referem à subdivisão do tempo de aplicação da corrente ao final do tempo de retenção do eletrodo e, os mesmos, foram incluídos com o intuito de avaliar a sua influência na aplicação da corrente de preaquecimento. Assim também, foram incluídos os ciclos de subida de corrente, que é o intervalo que se leva para que a corrente atinja o valor programado. Neste contexto, procurando avaliar sua

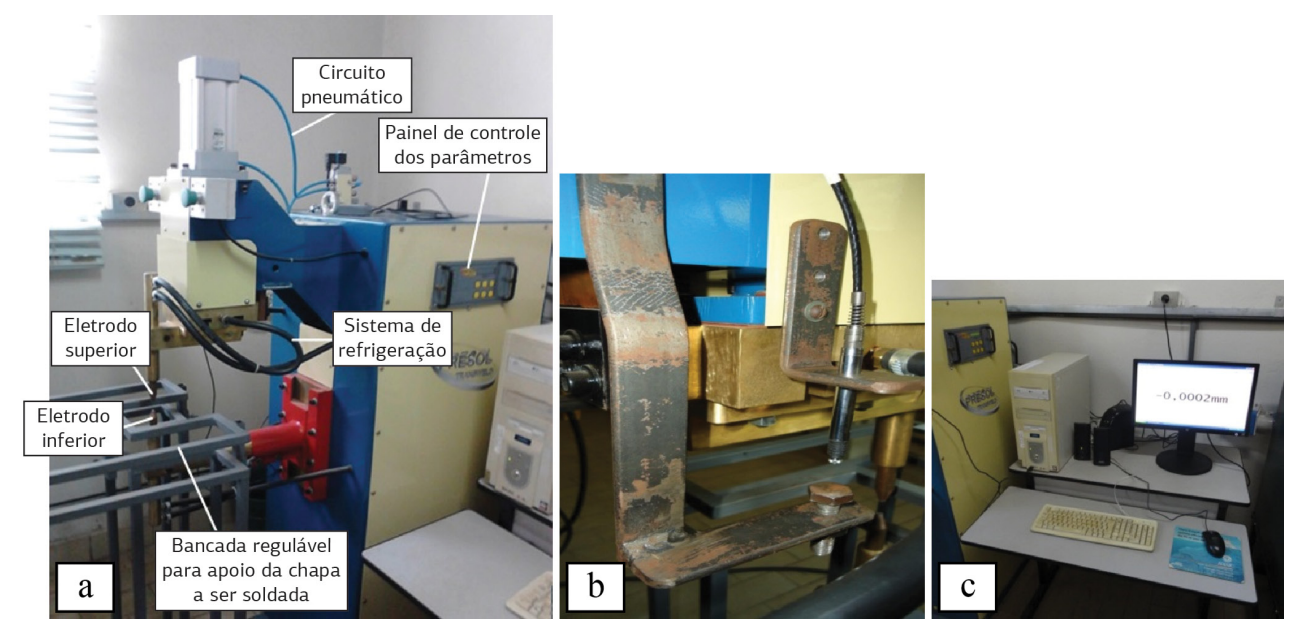

Figura 1. Sistema de leitura aplicado no deslocamento do eletrodo. (a) Equipamento de soldagem RSW; (b) sensor LVDT; (c) sistema de interface.

Tabela 1. Composição química do aço utilizado.

\begin{tabular}{ccccccc}
\hline Material & $\mathbf{C}(\%)$ & $\mathbf{M n}(\%)$ & $\mathbf{P}(\%)$ & $\mathbf{S}(\%)$ & Al (\%) & $\mathbf{Z n}\left(\mathbf{g} / \mathbf{m}^{2}\right)$ \\
Aço carbono USIGALVE-EEP-PC & 0,06 & 0,35 & 0,025 & 0,025 & 0,02 & $40-60$ \\
\hline
\end{tabular}

Fonte: Usiminas. 


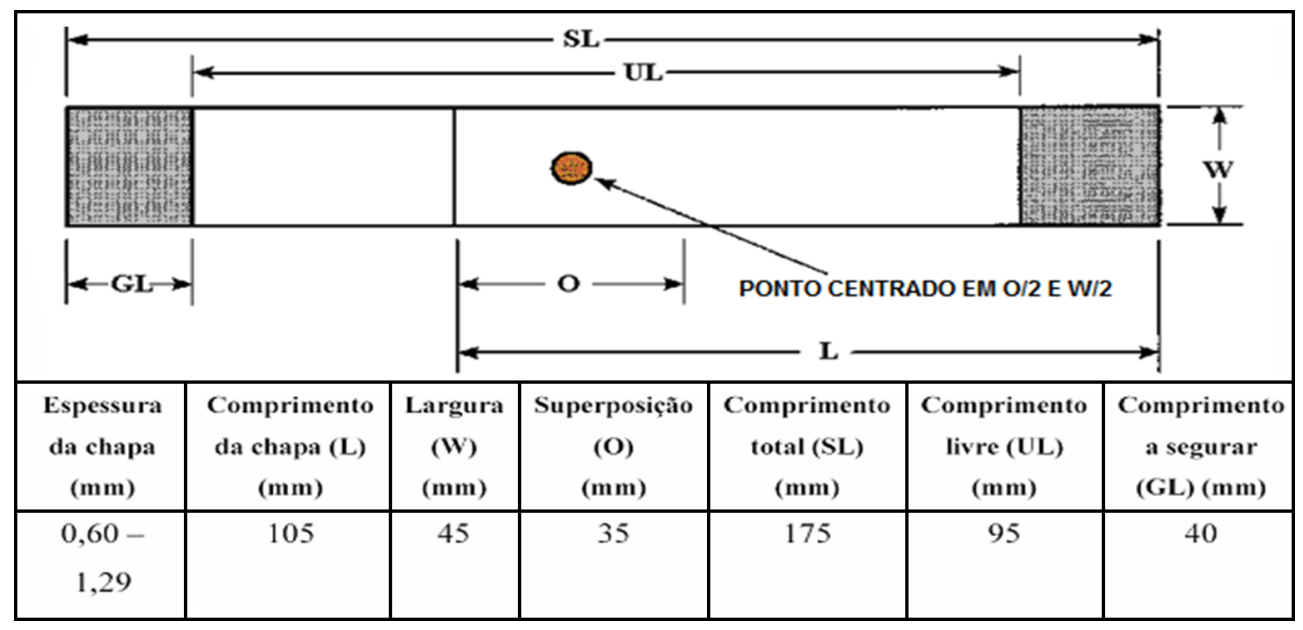

Figura 2. Especificações dimensionais dos corpos de prova (unidades em mm). Fonte: AWS (2002) Modificada.

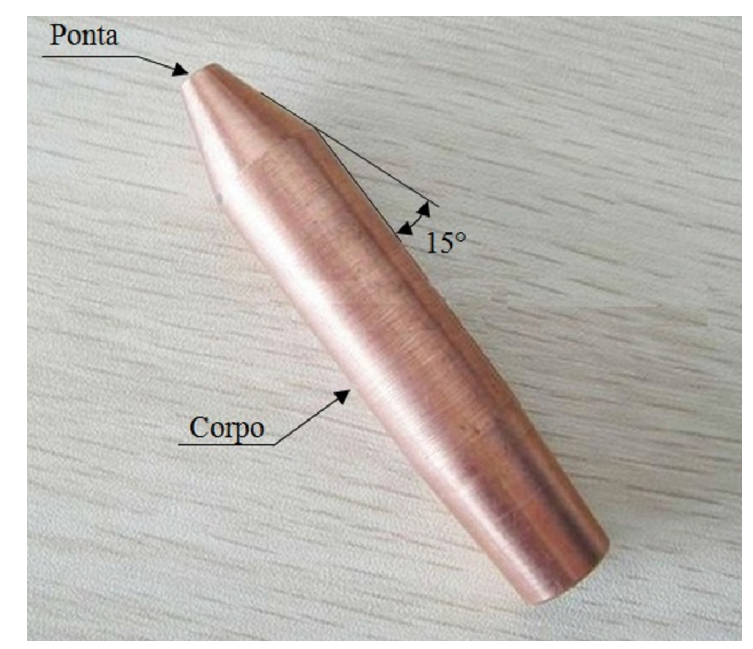

Figura 3. Eletrodo utilizado no experimento.

Tabela 2. Níveis dos parâmetros ajustados na primeira etapa.

\begin{tabular}{lclc}
\hline \multicolumn{1}{c}{ Descrição } & Valor & \multicolumn{1}{c}{ Descrição } & Valor \\
Pré-pressão 1 (ciclos). & 40 & Ciclo de revenimento. & 0 \\
Pré-pressão 2 (ciclos). & 40 & Corrente de revenimento (kA). & 0 \\
Ciclo de Preaquecimento. & $10-30$ & Pós-pressão (ciclos). & 0 \\
Corrente de preaquecimento (kA). & $1,2-5,4$ & Impulsos (ciclos). & $1-2$ \\
Ciclo de Solda. & 0 & Subida da corrente (ciclos). & $0-10$ \\
Corrente de solda (kA). & 0 & Descida da corrente. & 0 \\
Intervalo. & 0 & Pressão do eletrodo (MPa) & 0,43 \\
Resfriamento. & 0 & & \\
\hline
\end{tabular}

influência no preaquecimento, a subida da corrente é inserida de forma suave, até atingir o valor programado, o que evita o faiscamento e a ocorrência de expulsão do metal base, durante a solda [1].

Após a realização dos experimentos, os parâmetros que apresentaram influentes na fase de preaquecimento são mostrados na Tabela 3. Esta influência foi determinada pela variação no deslocamento linear do eletrodo durante o processo de aplicação da corrente de preaquecimento. Contudo, a pressão foi mantida constante tanto na primeira quanto na segunda etapa, tendo em vista o valor ótimo estabelecido por [13]. 
Tabela 3. Variação dos parâmetros ajustados na segunda etapa.

\begin{tabular}{lclc}
\hline \multicolumn{1}{c}{ Descrição } & Valor & \multicolumn{1}{c}{ Descrição } & Valor \\
Pré-pressão 1 (ciclos). & 40 & Ciclo de revenimento. & 0 \\
Pré-pressão 2 (ciclos). & 40 & Corrente de revenimento (kA). & 0 \\
Ciclo de Preaquecimento. & $3-30$ & Pós-pressão (ciclos). & 0 \\
Corrente de preaquecimento (kA). & $4,8-6$ & Impulsos (ciclos). & 1 \\
Ciclo de Solda. & 0 & Subida da corrente (ciclos). & 0 \\
Corrente de solda (kA). & 0 & Descida da corrente. & 0 \\
Intervalo. & 0 & Pressão do eletrodo (MPa) & 0,43 \\
Resfriamento. & 0 & & \\
\hline
\end{tabular}

\section{Resultados e Discussão}

\subsection{Validação do deslocamento do eletrodo como avaliador da ação de remoção em aços galvanizados}

Conforme descrito no item 2, é possível caracterizar fisicamente a remoção da camada de zinco, baseada no deslocamento do eletrodo de cobre, antes da soldagem do ponto propriamente dita [3]. Esta metodologia proposta foi neste trabalho explorada com o intuito de caracterizar esta mesma remoção, visto que, nas indústrias de forma geral, tais avaliações, são, via de regra, realizadas empiricamente. Desta forma, esta metodologia foi avaliada e explorada em detalhes para poder caracterizar, de forma mais aprofundada, a remoção da camada de zinco, os efeitos dos parâmetros de ciclo e a intensidade do preaquecimento nesta remoção para o aço galvanizado aqui estudado. Visto ser esta fase fundamental, não apenas para a qualidade final do ponto de solda, mas também para a garantia de uma maior vida dos eletrodos antes de uma fresagem, houve a necessidade de validar esta metodologia, o que será descrito na sequência.

A validação do método se mostra pela comprovação da remoção da camada de zinco, evidenciada pela formação de uma auréola [3] ao redor da zona de contato, que pode ser na interface interna (contato chapa/chapa) ou na interface externa (contato eletrodo/chapa) e, validado pelo deslocamento linear do eletrodo, que é representado por um gráfico em função da variação dos parâmetros de corrente (amperes) e número de ciclos ajustados na máquina de solda a ponto. Para a realização dos experimentos, dez corpos de prova foram preparados, conforme recomendação da [11] e a montagem de acordo com a Figura 2. A máquina de solda foi ajustada para realizar a pré-pressão (aproximação dos corpos de prova antes à entrada da corrente elétrica) e, a execução apenas da fase de preaquecimento, sem a fase de soldagem. Assim o objetivo desta etapa deve ser a avaliação da remoção do revestimento de zinco na chapa de aço galvanizada. Considerando os parâmetros descritos na Tabela 2, o equipamento de soldagem foi programado e, os resultados dos testes obtidos foram descritos na Tabela 4, onde os valores em negrito referem-se aos testes selecionados para validar esta primeira etapa.

À medida que os experimentos foram realizados, o nível da corrente de preaquecimento (Ipreaq) foi ampliado até atingir um limite mínimo onde ocorresse a remoção do zinco, considerando um nível de tempo de preaquecimento (Tpreaq) de 30 ciclos. Após esta etapa, a corrente foi aumentada em escalas menores, procurando assim, encontrar uma condição satisfatória de remoção do zinco, e também o limite máximo, onde que, a partir dele, ocorre à fusão do aço propriamente dita.

Observa-se na Tabela 4 que, a variação na subida da corrente observada entre o teste 6 e o teste 7 não apresentou uma diferença significativa para a fase do preaquecimento. 0 mesmo ocorre entre o teste 8 e o teste 9 onde a variação nos impulsos também não apresentou grandes diferenças visuais na remoção do zinco. Desta forma, em função dos resultados obtidos, procurou-se avaliar a possibilidade de aplicação da regra da inversão proporcional existente entre tempo e corrente de solda [14] somente para a fase do preaquecimento. Muito embora, a utilização de maiores correntes de preaquecimento favoreça remoções excessivas do zinco, a possibilidade de utilização de menores níveis de tempo de preaquecimento, é muito interessante principalmente no meio industrial onde a busca pelo aumento da produtividade do processo de soldagem é constante. Para tanto, níveis maiores dos parâmetros de preaquecimento para avaliação foram determinados na Tabela 3. 
É importante destacar que a união das chapas e a remoção excessiva não são o objetivo deste método e sim a remoção satisfatória do zinco (caracterizada como remoção ideal), observada quando há formação de uma auréola de zinco ao redor da zona de contato, sem vestígios visuais de inicio de fusão do metal base. Desta forma, para avaliar o deslocamento do eletrodo perante as condições mínimas, satisfatórias e máximas de preaquecimento, três testes foram escolhidos, sendo eles o teste 2 , o teste 3 e o teste 4 .

A Figura 4 abaixo, mostra o deslocamento do eletrodo no teste 2 . Nesta condição de preaquecimento não se observou nenhuma remoção da camada de zinco, porém na Figura 4b uma mancha escura caracteriza o início de uma pequena queima do zinco. Neste contexto, atingiu-se o limite mínimo. Fato este que pode ser retratado pelo gráfico na Figura 4a, caracterizado pela falta de perturbação no comportamento do deslocamento do eletrodo.

Comparativamente ao teste 2, no teste 3 houve o aumento da corrente de $3 \mathrm{kA}$ para 4,2kA sem alteração no tempo de preaquecimento. Portanto, observa-se na Figura 5 a uma maior perturbação no comportamento do deslocamento do eletrodo, tais perturbações são a presença nítida de vales e picos correspondente ao preaquecimento. Assim, o primeiro vale corresponde ao achatamento das asperezas da camada do zinco na interface interna [3], que é seguido por uma pequena expansão térmica (primeiro pico) com maior intensidade da camada de zinco em comparação ao material base [3]. Na sequência, o zinco atinge seu ponto de fusão e a pressão dos eletrodos empurra todo o zinco para fora da zona de contato interna, o que corresponde ao segundo vale. Nota-se, pela observação do teste 10 na Tabela 4, que a remoção do revestimento de zinco na interface externa, ocorre muito mais tarde do que na interface interna [3]. Desta forma, o segundo pico foi escolhido para determinar a remoção à interface externa. Ao final do segundo pico, houve a remoção completa do zinco na interface interna e externa. Assim, todo tempo excedido ao segundo pico torna-se desnecessário.

Tabela 4. Valores programados no equipamento de soldagem e os resultados obtidos.

\begin{tabular}{|c|c|c|c|c|c|c|c|}
\hline Teste & $\begin{array}{c}\text { Ipreaq } \\
\text { kA }\end{array}$ & $\begin{array}{l}\text { Tpreaq } \\
\text { ciclos }\end{array}$ & $\begin{array}{l}\text { Queima } \\
\text { do zinco }\end{array}$ & Impulsos & $\begin{array}{l}\text { Subida da } \\
\text { Corrente }\end{array}$ & $\begin{array}{l}\text { Observações da } \\
\text { Interface Interna }\end{array}$ & $\begin{array}{l}\text { Observações da } \\
\text { Interface Externa }\end{array}$ \\
\hline 1 & 1,2 & 30 & Não & 1 & 0 & Não removeu & Não removeu \\
\hline 2 & 3 & 30 & Sim & 1 & 0 & Remoção Parcial & Não removeu \\
\hline 3 & 4,2 & 30 & Sim & 1 & 0 & Remoção Ideal & Remoção Ideal \\
\hline 4 & 5,4 & 30 & Sim & 1 & 0 & Solda & Solda \\
\hline 5 & 5,4 & 30 & Sim & 1 & 10 & Solda & Solda \\
\hline 6 & 4,5 & 30 & Sim & 1 & 0 & Remoção Excessiva & Remoção Excessiva \\
\hline 7 & 4,5 & 30 & Sim & 1 & 10 & Remoção Excessiva & Remoção Excessiva \\
\hline 8 & 4,5 & 30 & Sim & 2 & 10 & Remoção Excessiva & Remoção Excessiva \\
\hline 9 & 4,5 & 30 & Sim & 2 & 0 & Remoção Excessiva & Remoção Excessiva \\
\hline 10 & 4,5 & 10 & Sim & 1 & 0 & Remoção ideal & Remoção parcial \\
\hline
\end{tabular}

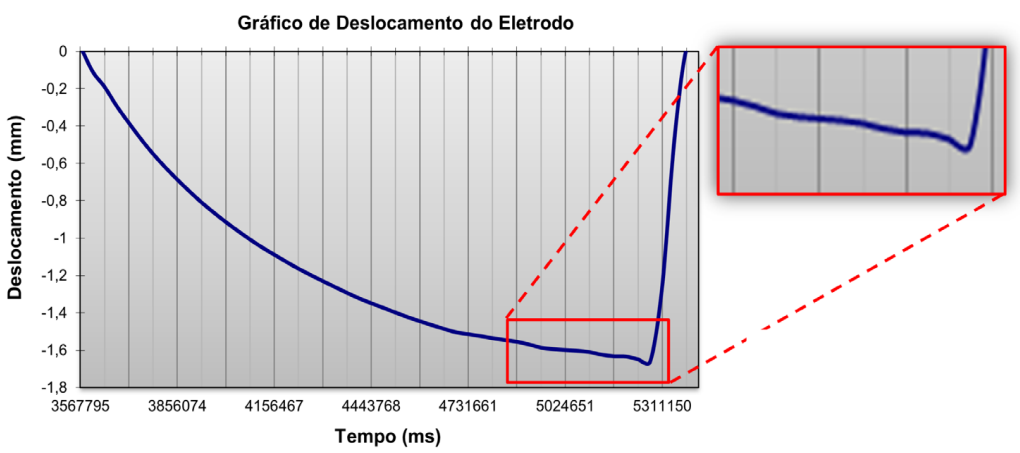

(a)

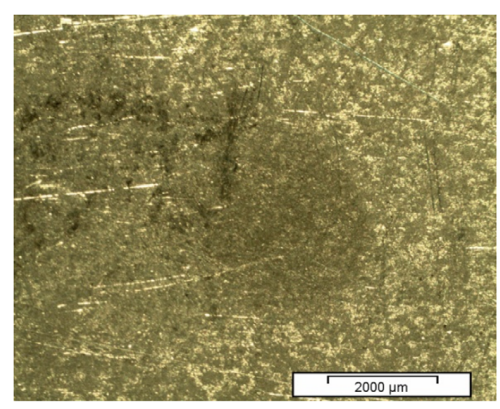

(b)

Figura 4. Teste $n^{\circ} 2$. (a) Gráfico de deslocamento do eletrodo; (b) zona de contato na interface das chapas. 
Aumentando o nível da corrente para 5,4 kA e mantendo um tempo de 30 ciclos, percebe-se pela Figura 6a, que esta condição gera a ação de limpeza nas interfaces interna e externa, maior do que a necessária. Comparada a Figura 5a resultando no início do processo de fusão do metal, mostrado na Figura $6 \mathrm{~b}$ em comparação a Figura 5b. Entretanto esta condição de remoção não é interessante, pelo motivo de utilizar um tempo de corrente a mais que o necessário.

Por outro lado, percebe-se ser possível determinar exatamente o tempo necessário para a ocorrência da limpeza ideal em um nível de aplicação de corrente. No caso da Figura 5 e da Figura 6, tal nível de tempo de preaquecimento poderia ser determinado pela Equação 1, considerando-se que 60 ciclos de aplicação da corrente equivalem ao tempo de $1 \mathrm{~s}$.

$$
y=\left(t_{f}-t_{i}\right)^{*} f
$$

Onde: $\mathrm{Y}$ - número de ciclos necessários [ciclos]; $t_{f}$ - tempo do segundo vale [ms]; $t_{i}$ - tempo do primeiro vale $[\mathrm{ms}] ; f$ - frequência elétrica da fonte alimentadora - $60[\mathrm{~Hz}]$.

Entende-se, portanto que, considerando os valores do primeiro vale e do segundo pico mostrado da Figura 6a, ao substituí-los na Equação 1, pode-se dizer que, é necessário um tempo de 13 ciclos para uma remoção satisfatória do zinco na interface interna e externa conforme mostrado na Figura 7 abaixo, ao invés dos 30 ciclos que foram utilizados para o teste 4, considerando um nível de corrente de 5,4 kA conforme mostrado anteriormente na Tabela 4.

Um detalhe importante a ser mencionado, observa-se na Tabela 4, em que, a remoção ideal do zinco iniciou a partir de um nível mínimo de corrente de 4,2 kA de Ipreaq utilizando 30 ciclos de Tpreaq, considerando as dimensões do eletrodo utilizado. Todavia, com a utilização de chapas de aço de menor espessura, torna-se necessário a utilização de diâmetros cada vez menores da ponta do eletrodo. Esta redução do diâmetro, aumenta a densidade de corrente e, como consequência aumenta a geração de calor, o que implica na redução dos tempos

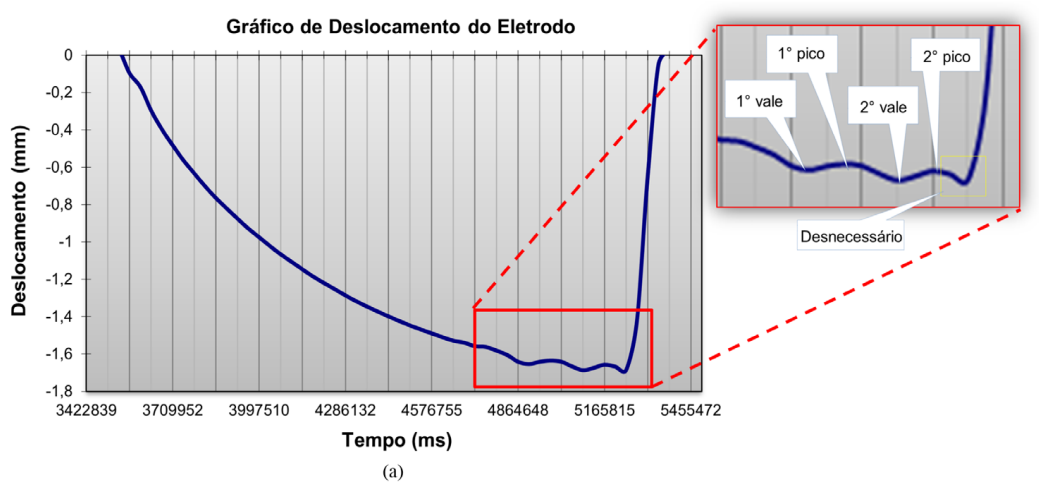

(a)

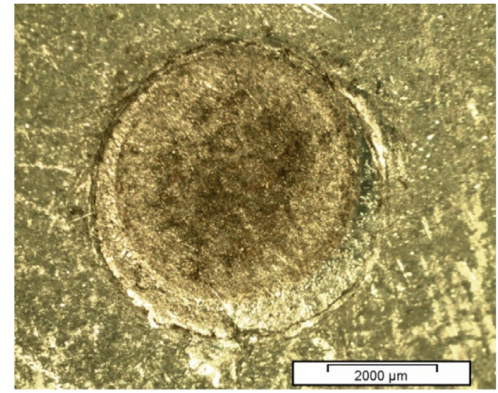

(b)

Figura 5. Teste $n^{\circ}$ 3. (a) Gráfico de deslocamento do eletrodo; (b) zona de contato na interface das chapas.

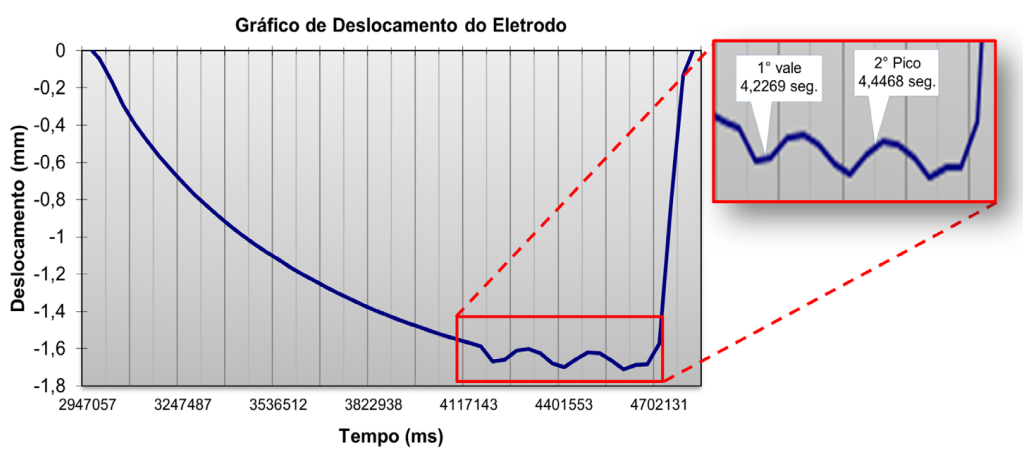

(a)

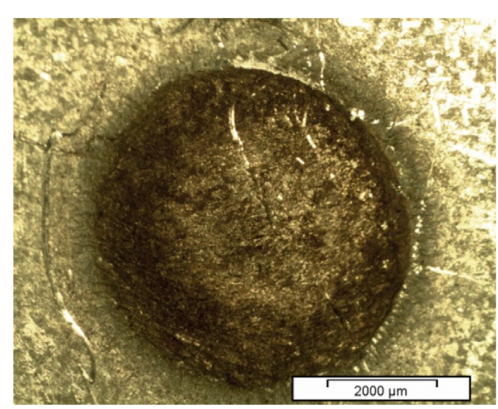

(b)

Figura 6. Teste $n^{\circ}$ 4. (a) Gráfico de deslocamento do eletrodo; (b) zona de contato na interface das chapas. 
de preaquecimento. Desta forma, uma melhor escolha da taxa de amostragem de leitura do sensor, juntamente com uma análise mais detalhada dos sinais, poderia mostrar mais detalhes e com maior precisão, o gráfico de deslocamento do eletrodo.

Outro detalhe importante refere-se à migração do zinco para o eletrodo durante o processo RSW. Neste caso, [4] observou que o aporte térmico possui relação direta com o desgaste e, a formação de latão na ponta do eletrodo. Neste contexto, a redução do número de ciclos demonstrada pela Equação 1, culmina no aumento da vida útil do eletrodo.

\subsection{Determinação do preaquecimento gerado pelos sinais de deslocamento do eletrodo}

Nesta segunda etapa do trabalho, o envelope operacional é formado por um conjunto de parâmetros de preaquecimento, onde o valor escolhido pode resultar em uma remoção da camada de zinco. Desta forma, os registros da expansão térmica do material coletados pelo sensor LVDT serão plotados em um gráfico em seus níveis de corrente ( $\mathrm{kA}$ ) e tempo (ciclos), com o intuito de demonstrar que é possível encontrar parâmetros de preaquecimento objetivando a remoção do zinco na interface interna (zona de contato chapa/chapa) e na interface externa (zona de contato de chapa/ eletrodo) pelo sinal de deslocamento do eletrodo.

No primeiro momento, pode-se considerar como um parâmetro de confirmação da remoção ideal do zinco em ambas as interfaces, a formação de uma auréola ao redor da zona de contato conforme mostrado na Figura 5b. Neste contexto, observa-se também uma diferença aparente de tonalidade entre a chapa de aço e o zinco, na medida em que o revestimento é removido. Estas características também podem ser observadas em experimentos conduzidos por [6], mostrando a ocorrência da queima do zinco, evidenciando que, na técnica do "Burn Zinc", o zinco é deslocado para a região ao redor do ponto de solda em que, neste caso, está representado pela zona de contato presente nas interfaces interna e externa. A Figura 8 mostra nitidamente o revestimento de zinco (representado pela cor escura) está depositado na superfície de uma chapa de aço galvanizado.
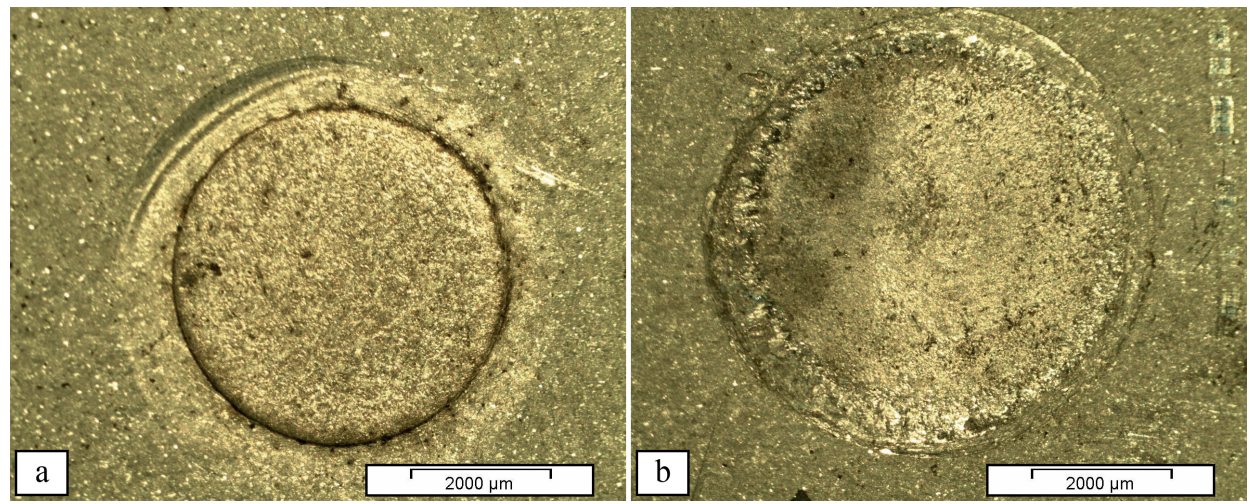

Figura 7. Remoção ideal com 13 ciclos e 5,4 kA. (a) interface externa; (b) interface interna.
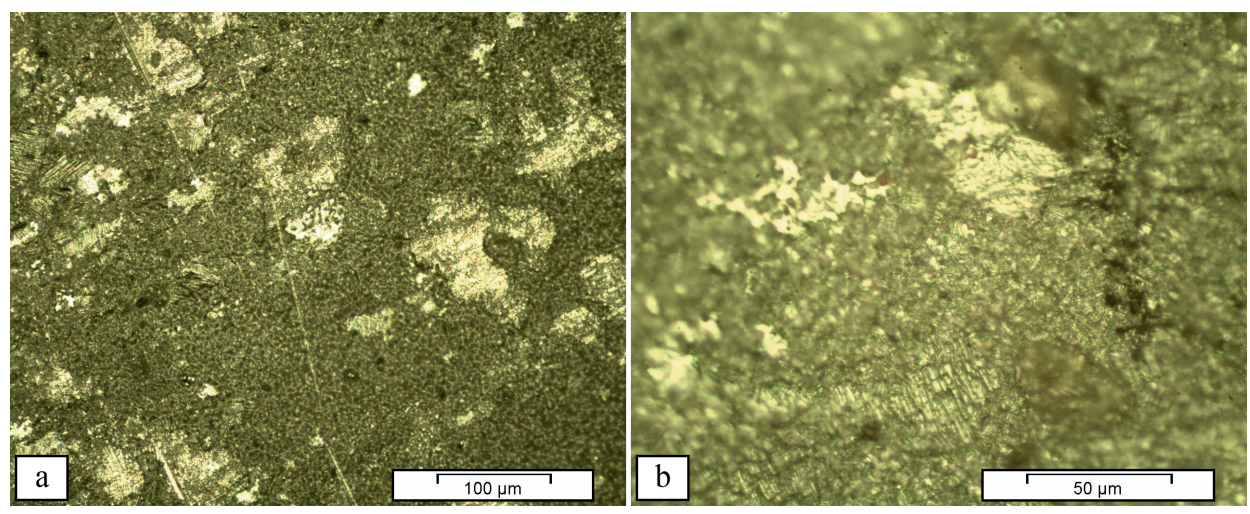

Figura 8. Revestimento de zinco. Ampliações: (a) 200 vezes; (b) 500 vezes. 
O zinco é representado pela cor escura e a chapa de aço pela cor clara. Nas Figuras 8a e b observa-se que a superfície está toda tomada pelo zinco, devido a grande incidência da cor escura. Desta forma, para efeito comparativo, as Figuras 9 e 10 mostram uma condição visual padrão em que, um aumento gradativo do tempo (ciclos) de preaquecimento mantendo-se a corrente (\%kA) constante, pode resultar na formação da auréola de zinco, caracterizando a remoção do zinco propriamente dita. Na Figura 9a e b, observa-se pouca diferença entre as cores clara e escura. Neste caso não houve remoção do zinco, mas somente uma pequena queima do revestimento. Isto é evidenciado comparando a Figura 9 com a Figura 8.

Aumentando o tempo para 20 ciclos, observa-se na Figura 10a e b uma grande diferença entre a cor clara e a escura, após a aplicação do preaquecimento. Neste exemplo, é nítida a formação de uma auréola de zinco ao redor da zona de contato na interface interna. Fato este que, comprova uma adequada remoção do zinco para esta interface. Comparativamente a Figura 8 b, a Figura 10c apresenta pouco revestimento de zinco (representado pela cor escura). Todavia, uma pequena quantidade de zinco residual se mantém sobre o metal base na zona de contato, resultado este em concordância com observado por [3].

Em função dos resultados observados, o equipamento de soldagem foi ajustado considerando os níveis dos parâmetros descritos na Tabela 3, para realizar apenas a etapa de preaquecimento, com o intuito de se obter os limites inferiores e superiores necessários à remoção do zinco. A preparação das amostras e realização dos testes seguiu conforme descrito no item 2. Após cada experimento realizado, as amostras foram separadas umas das outras e classificadas de acordo com os padrões visuais estabelecidos na Figura 4b, Figura 5b e Figura 6b, objetivando uma avaliação visual nas interfaces interna e externa do ponto de solda. Para cada experimento realizado, o comportamento da expansão térmica foi aquisitado pelo sensor LVDT. O Microsoft Excel ${ }^{\circledR}$ foi utilizado para estratificar os resultados que, depois, foram quantificados pela Equação 1. Todos estes resultados foram dispostos na Tabela 5 abaixo.

Na Tabela 5, as colunas referentes às observações das interfaces interna e externa foram criadas tendo como base os padrões visuais descritos anteriormente. Observa-se também, que alguns testes obtiveram a queima do zinco, porém apresentaram remoção parcial conforme mostrado na Figura 4b, o que não é desejado para o preaquecimento. Desta forma, os valores de tempo de preaquecimento dos testes que apresentaram a remoção ideal ao menos na interface interna foram utilizados para a Equação 1 e, mostrados na coluna Y, na Tabela 5.
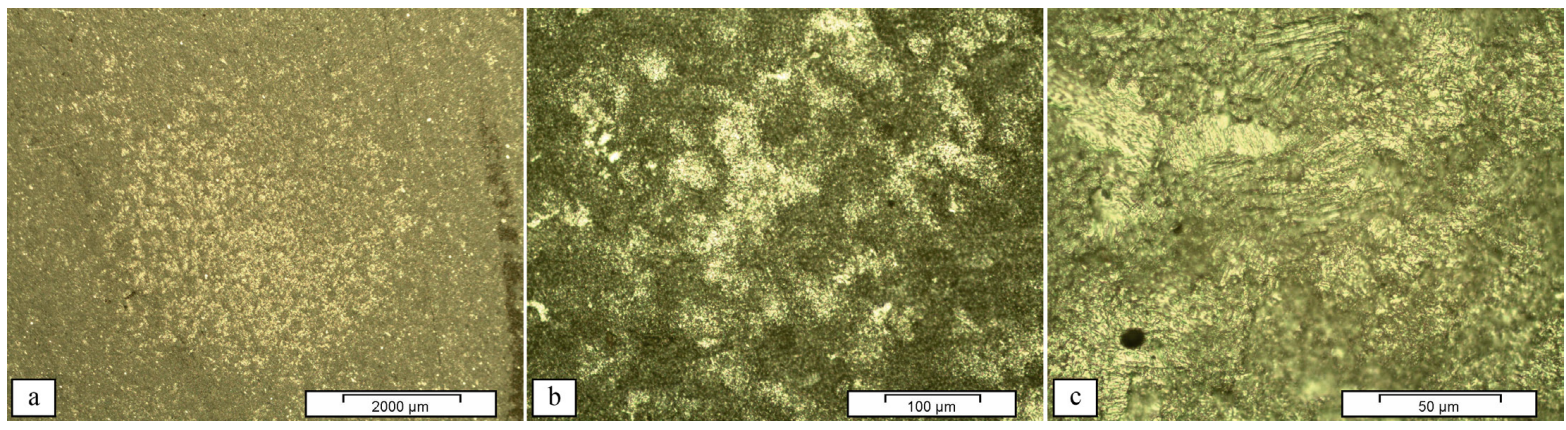

Figura 9. Remoção parcial com 10 ciclos e 4,2kA. Ampliações: (a) 15 vezes; (b) 200 vezes; (c) 500 vezes.
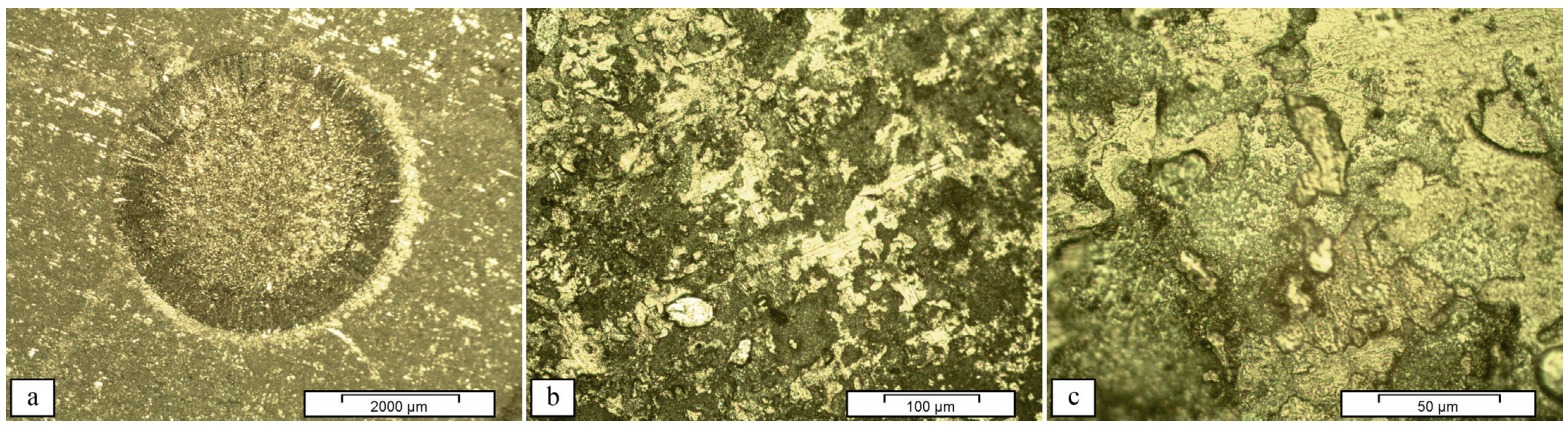

Figura 10. Remoção ideal com 20 ciclos e 4,2kA. Ampliações: (a) 15 vezes; (b) 200 vezes; (c) 500 vezes. 
O envelope operacional pode ser ilustrado na Figura 11, que tem por objetivo, demonstrar de uma forma gráfica a observação dos valores de Y para cada valor de corrente aplicado.

Considerando que a norma [14] descreve que, quanto maior o nível da corrente (kA) utilizada menor é o nível do tempo (ciclos) necessário para a realização de uma solda a ponto, a Figura 11 demonstra de forma nítida que esta afirmação também e válida para a realização do preaquecimento. Observa-se que, dentro dos limites do envelope operacional, uma condição de remoção ideal da camada de zinco nas interfaces interna e externa da chapa de aço é encontrada. Neste contexto os parâmetros de Tpreaq (ciclos) e Ipreaq (kA) que abrangem todo canto inferior esquerdo na Figura 11 até os limites do envelope operacional, apresentaram uma condição inadequada de remoção do zinco nas interfaces. Porém níveis de tempo e corrente que estão próximos aos limites do gráfico, podem apresentar remoção ideal somente na interface interna. Por outro lado, os parâmetros que abrangem todo canto superior direito até os limites do envelope operacional, apresentaram uma condição excessiva de remoção do zinco nas duas interfaces, o que não é interessante para a fase de preaquecimento. Entende-se, portanto que, quando se distancia destes limites do envelope operacional mais excessiva é a remoção do zinco, podendo chegar até a fusão o metal base.

Tabela 5. Valores de preaquecimento obtidos.

\begin{tabular}{ccccccc}
\hline Testes & $\begin{array}{c}\text { Ipreaq } \\
\text { kA }\end{array}$ & $\begin{array}{c}\text { Tpreaq } \\
\text { ciclos }\end{array}$ & $\begin{array}{c}\text { Queima do } \\
\text { zinco }\end{array}$ & $\begin{array}{c}\mathbf{Y} \\
\text { ciclos }\end{array}$ & $\begin{array}{c}\text { Observação da } \\
\text { interface interna }\end{array}$ & $\begin{array}{c}\text { Observação da } \\
\text { interface externa }\end{array}$ \\
01 & 4,8 & 7 & Sim & - & Remoção parcial & Remoção parcial \\
02 & 4,8 & 10 & Sim & 14 & Remoção ideal & Remoção parcial \\
03 & 4,8 & 20 & Sim & 17 & Remoção ideal & Remoção ideal \\
04 & 4,8 & 30 & Sim & 16 & Solda & Solda \\
05 & 5,4 & 3 & Não & - & Não limpou & Não limpou \\
06 & 5,4 & 5 & Não & - & Não limpou & Não limpou \\
07 & 5,4 & 7 & Sim & 11 & Remoção ideal & Remoção parcial \\
08 & 5,4 & 10 & Sim & 11 & Remoção ideal & Remoção ideal \\
09 & 5,4 & 20 & Sim & 14 & Solda & Solda \\
10 & 6 & 5 & Sim & - & Remoção parcial & Remoção parcial \\
11 & 6 & 7 & Sim & 10 & Remoção ideal & Remoção parcial \\
12 & 6 & 10 & Sim & 11 & Remoção ideal & Remoção ideal \\
13 & 6 & 20 & Sim & 12 & Solda & Solda \\
\hline
\end{tabular}

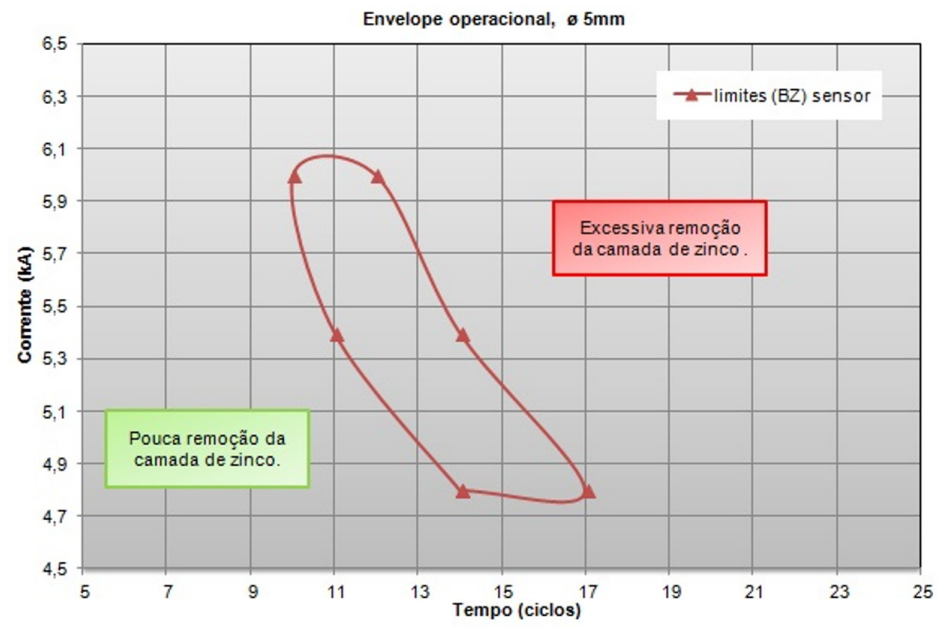

Figura 11. Gráfico dos envelopes operacionais. 


\section{Conclusões}

Baseado nos resultados obtidos neste trabalho, algumas conclusões podem ser feitas sobre esta metodologia:

- A parametrização do preaquecimento pela leitura do deslocamento do eletrodo se mostrou um eficiente método de otimização dos parâmetros de "Burn Zinc" permitindo a caracterização da remoção do zinco tanto na interface interna como na externa.

- Os resultados gerados durante a validação do método mostraram que a remoção ideal do zinco inicia-se a partir de nível mínimo de corrente de 4,2 kA de Ipreaq utilizando 30 ciclos de Tpreaq, considerando um diâmetro de $5 \mathrm{~mm}$ na ponta do eletrodo.

- A regra da inversão proporcional entre o tempo (ciclos) e a corrente (kA) de solda, pode ser utilizada durante a fase de preaquecimento, ou seja, quanto maior o nível de corrente menor o tempo de pré-aquecimento.

- Os resultados obtidos neste experimento referem-se à chapa de aço galvanizado por eletrodeposição. Porém, existem outros tipos de material, revestimentos e processos de galvanização em que este método pode ser aplicado, para determinar o número de ciclos necessário a uma remoção ideal do zinco na fase de preaquecimento.

\section{Agradecimentos}

Os autores gostariam de agradecer a UNIFEI, ao também ao Departamento de Pós-Graduação em Engenharia Mecânica, a Fapemig e a Capes pelos recursos dispensados e apoio para a realização deste trabalho.

\section{Referências}

[1] Marques PV, Modenesi PJ, Bracarense AQ. Soldagem fundamentos e tecnologia. Belo Horizonte: Ed. UFMG; 2009. p. 293-306.

[2] Pereira MA, Ferreira MJ, Loureiro A, Costa MDJ, Bártolo JP. Effect of process parameters on the strength of resistance spot welds in 6082-T6 aluminium alloy. Materials \& Design. 2010;31(5):24542463. http://dx.doi.org/10.1016/j.matdes.2009.11.052.

[3] Gedeon SA, Eagar TW. Resistance spot welding of galvanized steel: Part II. Mechanisms of spot weld nugget formation. Metallurgical Transactions. B, Process Metallurgy. 1986;17(4):887901. http://dx.doi.org/10.1007/BF02657152.

[4] Guedes JB, Gonçalves RA, Scotti A. Avaliação de desgaste de eletrodos em solda a ponto por resistência de chapas galvanizadas. Soldagem \& Inspeção. 2005;10(2):72-78.

[5] Babu SS, Santella ML, Feng Z, Riemer BW, Cohron JW. Empirical Model of Effects of Pressure and Temperature on Electrical Contact Resistance of Metals. Science and Technology of Welding and Joining. 2001;6(3):126-132. http://dx.doi. org/10.1179/136217101101538631.

[6] Nascimento VC, Scotti A. Metodologia para parametrizar e avaliar a técnica da "Burn-Zinc" no processo de soldagem a ponto por resistência. Soldagem \& Inspeção. 2010;15(1):11-21. http://dx.doi.org/10.1590/S0104-92242010000100003.

[7] Wang $H$, Zhang $Y$, Chen $G$. resistance spot welding processing monitoring based on electrode displacement curve using moving range chart. Measurement. 2009;42(7):1032-1038. http://dx.doi.org/10.1016/j.measurement.2009.03.005.
[8] Lee SR, Choo TJ, Lee TM, Kim MH, Choi SK. A quality assurance technique for resistance spot welding using a neuro-fuzzy algorithm. Journal of Manufacturing Systems. 2001;20(5):320328. http://dx.doi.org/10.1016/S0278-6125(01)80051-0.

[9] Dennison AV, Toncich DJ, Masood S. Control and processbased optimization of spot-welding in manufacturing systems. International Journal of Advanced Manufacturing Technology. 1997;13(4):256-263. http://dx.doi.org/10.1007/BF01179607.

[10] Ling S-F, Wan L-X, Wongn Y-R, Li D-N. Input electrical impedance as quality monitoring signature for characterizing resistance spot welding. NDT \& E International. 2010;43(3):200-205. http:// dx.doi.org/10.1016/j.ndteint.2009.11.003.

[11] American Welding Society - AWS. Recommended practices for test methods for evaluating the resistance spot welding behavior of automotive sheet steel materials. Florida: AWS; 2002. (AWS/SAE D8.9M:2002).

[12] Resistance Welder Manufacturers Association - RWMA. Eletrodos e ferramentas utilizadas no processo de soldagem por resistência elétrica. Miami: RWMA; 2002. p. 1-13.

[13] Amaral FF. Monitoramento da qualidade na soldagem a ponto por resistência elétrica de chapas de aço galvanizadas baseado em análise de experimentos [dissertação de mestrado]. Itajubá: Universidade Federal de Itajubá; 2011.

[14] American Welding Society-AWS. Welding Handbook. Miami: AWS; 1998. p. 233-332. 